International Journal of Scholarly Papers for Media and Communications

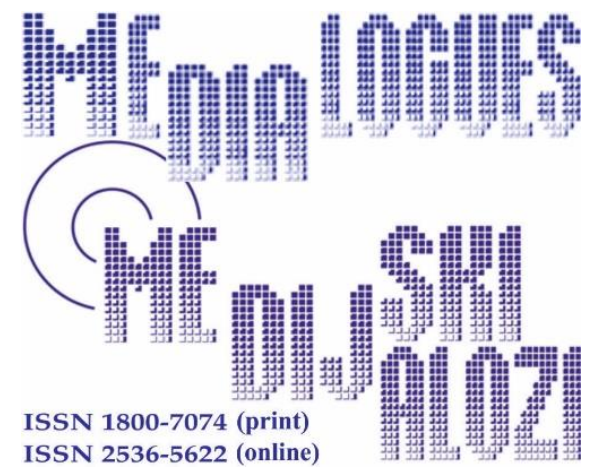

Ratajczak, M. (2013), „Network Communication and Ethnic Communities in Poland”, Media Dialogues / Medijski dijalozi, Vol. 14, No. 2, pp. 25-37.

\title{
Network Communication and Ethnic Communities in Poland
}

\author{
MAGDALENA RATAJCZAK, PhD
}

Institute of International Relations, University of Wroclaw, Wroclaw, Poland

\begin{tabular}{|c|c|l|}
\hline $\boldsymbol{A} \boldsymbol{R} \boldsymbol{T} \boldsymbol{I} \boldsymbol{C L} \boldsymbol{E}$ & Received: November 21,2021 & Revised from: December 19, 2021 \\
$\boldsymbol{I} \boldsymbol{N} \boldsymbol{F} \boldsymbol{O}$ & Accepted: January 19, 2021 / & Available online: April 15, 2021 \\
\hline $\boldsymbol{D O I}$ & doi.org/10.14254/1800-7074/14-2/2 \\
\hline
\end{tabular}

\section{ABSTRACT}

The paper discusses the principles of the activity of ethnic groups in the area of the new media in poland. The paper aims at presenting the internet as a alternative tool for ethnic groups and migrants. The internet helps them to create new ,virtual” ethnic identities. The paper includes also theoretical discussion of on-line communication and concepts of ethnic identities.

KEYWORDS: Network, communication, Poland, ethnic communities 


\section{INTRODUCTION}

Experience that has been gained so far has shown that using traditional, old media is still quite common among national and ethnic minorities in Poland. What is noticeable is that new forms of communication in the domain of the new media are being sought. An analysis of the extent to which new communication tools are used and how the selected ethnic minorities in Poland are active on the net. The aim of this analysis is to indicate how varied communication tools are used by minority groups in Poland. At the same time the different aims that are served by this can be observed.

Selected examples illustrate how expert use can be made of global communication tools for the use of local communities. This means that we can, at the same time, make use of global media in order to create small, local, ethnic communities. K. Krzysztofek concurs with the view that after a period of infatuation with the global reach of information, more and more people are reaching for the internet to contact one's own, local community. In the virtual reality new local communities are appea- ring, with the global internet existing on a local or 'glocal' basis.

In analyzing the behavior of the users of social network sites P. Levinson (2010, pp. 200-204) has noted that cyberspace has become a place where special communities are taking shape. The users of the new media create characteristic communities, often termed as 'virtual communities'. What is particularly valuable, from the perspective of ethnic communities, is that the internet and the "virtual communities' created in its space are becoming a significant element of the public sphere. It can be said that they contribute to the creating of a multi-ethnic public sphere, in which a cultural heterodoxy is seen as a common good accepted by the majority as well as minority.

\section{ET@NET}

In recent times the internet has been a harbinger of changes in the way ethnic communities communicate. There are different degrees to which these groups perceive the need to and possibilities of reaching for the new media. The mass society and networks have both a global, as well as local reach. In society webs create virtual times and spaces. Direct communication remains, in many respects, the most important type of communication. It is, however, gradually becoming supplemented by indirect communication. Apart from the existing, traditional mass media, new forms of group communication are developing incyberspace on both an interpersonal and a mass level, including chat lines and internet communicators as well as virtual communities, united by common interests. Activity on the web is not replacing direct contacts but is more and more often supplementing other types of communication. One of the most significant trends in the web society is the growing significance of 
the significance of interpersonal relationships. The effects of these are clearly visible in the economy, politics or culture (Van Dijk, 2010, pp. 56-62).

The internet also helps foster relations based on common goals, interests or ideas. What is created in this way is 'virtual web communities'. As W. Burszta notes the awakening in ethnic awareness is not only a phenomenon that is evident in the con- text of the internet and by means of using this type of communication. The move of communications to the web was not the only factor that contributed to these changes. What is significant, however, is the role, which new technology plays in these processes. „Thanks to the internet the phenomena of ethnic, social and cultural integration have been given impetus. People can communicate more quickly and easily and exchange information. This is the first and significant step to meetings and undertakings in the real world. In Poland many ethnic and national minority groups, including Armenians, Tartars, Karaims or the Lemko people, have their own web sites, which play the important role of a post box and give access for users to reach information of importance to them. The internet today is an impetus for many social phenomena, which does not, of course mean, that it is their sole reason or the source of all social changes" (Wywiad \& Bursztą, 2005). What is certain, however, is that it plays a significant part in shaping cultural identity and pride in belonging to a social group. It can be seen that there is no agreement as to how the internet can be defined from a social point of view. It can be seen, following the view of M. Castells, that it is a new multi-medial means of communication between people and institutions. Another way of looking at the internet is as a new community, which exists in cyberspace. It has its own institutions, norms and culture. The possibility that it creates for meeting social needs is the preordinate factor that indicates that the internet should be treated as a society (Nowak \& Krejtz, 2006, pp. 6-7). W. Gustowski (2012, pp. 97-106) is of the view that internet communities should be divided accor-ding to different criteria. From the perspective of the activity of ethnic groups on the web I would like to point to a number of types of e-communities:

- A virtual communityc- i.e. a group of people who use the net as the only means of communication. These are people who are not in everyday contact and often live in distant countries. A good example of these can be served by dispersed ethnic groups or religious groupings, such as trans-national Islam.

- Support communityc- the internet serves as a means of rapid, constant communication for real communities. Ethnic groups have contact but the internet serves as an additional tool within the group as well as with other communities.

- Discussion communities - groups of people for whom the main aim i san exchange of views and information. These are usually centered on a web site with a discussion forum and also make use of discussion lists.

- Civic communities- groups of people whose aim is to disseminate information to a wider audience. Their activity is the result of a certain sense of mission. In this case there is also an expectation that the texts will be commented on. 
The theoretical framework in research on diasporas is based on categories of culture and national identity. What follows from it is that diaspora media, with transnational media in the forefront, which can include the websites, build a platform which facilitates the construction of emotional links and a feeling of belonging to a certain 'imagined' transnational community (Bailey et al., 2012, p. 73). It is also, at the same time, a platform where global mixes with local and where identities of being a migrant and a new citizen are negotiated. The new media play a very intensive part in building a certain 'new ethnicity', as a result, among others, of negotiating a cultural identity.

The internet today provides great opportunities for those communities, which for economic, technical or geographic reasons lack access to other types of media. The internet is used in many different ways. The main communication tools are web sites, discussion for a and blogs. Ethnic communities are publishing papers online, radio and TV programmes online ever more frequently. What is worthy of note is the crea- tion of communities by means of social media. Often Facebook contacts serve as a bridge between the current homeland and their parents 'or grandparents' country of origin (Vittadini et al., 2013, pp. 61-67).

T. Eriksen (2011) pay attention on four diverse communities. They are used the inter- net as the important communications tool:

- Nations which have lost their territory.

- Nations which are for political reasons dispersed.

- Nations with large temporary diasporas overseas.

- Nations where many citizens work temporarily or permanently abroad.

In addition to the classification articulated by Eriksen above, I would add two more communities where the internet is playing an increasing role. First of all this is the sphere of indigenous communities, for whom the internet has become an important communication tool-both within and outside the group. The internet is a platform for active participation in public discourse, even that, which is ignored by the mainstream media, concerning indigenous communities. It is often the case that such communities are dispersed and therefore contact is more difficult. We will later come to the cases of the Jewish and German communities in Poland as a case in point. As W. Burszta points out: „One of the first groups who appreciated the huge potential of the inter-net and to make use of it were the Native Americans, in particular the Oneida tribe. Their experience was later used by other indigenous cultures. The internet proved to be the best me- ans of integrating the people from the Oneida tribe. They are dispersed throughout the world and the net enabled them to communicate and to take effective, joint actions. In this way they were able to create a common literary language and create a cultural elite. They were able to effectively influence the US administration in order to obtain necessary information but already as the 'Oneida nation" (Bursztą, 2005). Their example has been followed by 
many other ethnic groups. The phenomenon of using the internet by indigenous groups is widespread in the USA.

A second example are small language minorities the speakers of which treat the internet as a tool to support actions taken to protect their language from extinction. These language and indigenous minorities often find access to the traditional media difficult because of their small numbers. The internet has provided them with a platform to talk about themselves, sometimes to remind others about their history. What is interesting it is also possible to find pages on the web created by people who do not belong to the given group but want to support them, help preserve the language, get to know its users and their history. These undertakings give a chance to give the language a life-line and what is important make it possible enable it to be studied. Linguists have drawn attention to this on-line communication. It will probably not be possible to save most languages threatened with extinction but it is important to study and document the existence of as many as possible. Later in the article I will analyze the case of the Kaszub community in Poland.

\section{POLISH ET@NET}

Poland is one of the European countries with the quite low percentage of ethnic and national minorities. According to the Census of Population from 2011 acknowledged minorities make up 3.8 per cent of the Polish population.

The Act on national and ethnic minorities and regional language, which was adopted by the Parliament in 2005 recognizes:

- nine national minorities: German, Russian, Belorussian, Lithuanian, Czech, Slova- kian, Ukrainian, Jewish, Armenian,

- four ethnic minorities: Roma, Karaims, Lemko and Tatars,

- one community which used regional language - Kashubian.

But Poland is inhabited by the representatives of many other ethnic groups: Greek, Chinese, Vietnameese.

Minority communities in Poland, using different sources of financial support, are reaching more and more often for the tools offered by the new media. The majority of the national and ethnic minorities have their websites or pages on the net. Most often these are pages of organisations or minorities associations. In this part of the article I'd like to point to three selected examples of the use of the media by the German, Jewish minorities and the Kaszub community. Each one of them constitutes a distinct example of the use of the new media. The subject of the analysis are the German www.vdg.pl, Kaszub www.naszekaszuby.pl and the Jewish case of the Bente Kahn Foundation www.fbk.org.pl. The websites, which are the subject of analysis are not the only ones that these communities have at their disposal, but are noteworthy for a number of reasons. 
The first one of the cases under discussion is the www.vdg.pl website- edited by the German community in Polish and German. It is called The website of the German people in Poland. It is an example of the new media being used in a skilled way. Below - a brief description of the website. At the top of the page there are the following page directories:

- News, which is divided into the different regions, in which the German community lives.

- Politics, in which government agreements. Acts of Parliament, Bills and other sig- nificant documents on the national and European level.

- Culture - with information about annual pilgrimages of the German community and detailed information about weekend courses for children, meetings at community centres, seminars and conferences.

- About us - this is information about the German community in numbersaccording to the census and the factual situation. In this section there are news about the Union of German Communities. A history of union is presented. On the map one can find all the German minority groupings, which are active at the local level. Next is the strategy for development between 2010-2015 and the organisation's partners in Germany and Poland. There also pieces of information about bilingual gminas and roadsigns.

- Education- a section in which the legal basis for education for the minorities is outlined. One can also find practical information about minority language teaching and a list of schools where bilingual teaching takes place.

- In the Media section there is detailed information about all radio and TV broadcasts addressed at the German community. Furthermore there is a list of press publications edited by the German Social and Cultural Associations in Poland. In this section there is also press information and press releases of the German minority in Poland. There is also information about a newsletter and details of how to order it.

- Youth - in this section there is information about German minority youth organisa- tions.

- Medioteka - in which broadcasts of the Schliesen Journal and Schliesen Kompakt. There is also a photo gallery of the numerous conferences, meetings and workshops of the German minority.

- The last section on Becoming a Member provides information on how to join the German organizations.

On the main page on the top left side there are a lot of slides with the latest information on various topics. The most important information is under the slides and is divided into the latest and older information. There is a banner about the German Bundestag elections due in September 2013 with instructions on how to register and vote. The left hand column is completed with the blog by MP Bernard Gaida with the four most recent entries. 
The right side is divided into numerous entries, maps and links. Just below the links is a map with details about the German minority in the different parts of the country. There is a timetable of events and a map entitled Find an organisation in your region. There also links to the TV journal Schliesen Journal, the „Wochenblatt” paper and the Pro Future production team. Below there is a section entitled Last Commented with a link to the Mittedrin programme. Under that is the Ask a question section. There is information that the website has been financed by the Ministry of Internal Affairs of the German Federal Republic. The Union of German SocialCultural Associations is on Facebook and has over 360 people who like it (as of 09.07.2013).

The website covers a wide range of subjects with political, cultural and social areas among these covered. This does not stand in the way of a clear and legible style. In using the classification put forward by W. Gustowski in this article it can be said that the site supports the shaping of a virtual, supporting civic and discussionbased community. In this way www.vdg.pl is a communication tool for a varied and dispersed community living in the western, northern and southern parts of Poland. It is also a platform for shaping a supporting community as we are dealing with a group that uses other very active forms of communication acting through numerous associations and organisations. The internet is also a conduit for contact with other communities. Most certainly the site constitutes a discussion forum for an exchange of ideas and information. We are also dealing with a group that wishes to assert its separate status and aims to disseminate information to the wider public. Their action stems from a certain sense of mission. This is clear from commentaries, discussions . and questions asked.

Another example is provided by the Pomeranian community site www. naszekaszuby.pl. On the main page is the Kaszebsko Jednota banner- the association of people of the Kaszub nationality. Below is the banner of the Year of Zrzesincy (1933-2013 Zrzesince First for Kaszuby), which is being commemorated in 2013. In the middle of the page is the category of We recommend in which two books by Artur Jablonski, a well-known Kaszub journalist and activist are advertised. The first, entitled Namerkony (Marked), is described as the first story in the Kaszub language for a number of years and Kaszubi. Wspolnota Narodowa (Kaszubi. A national community). Both were published in 2013. Below there are three more categories News, Latest Comments and Forum - latest statements (news and forum is also contained in links at the top of the page).

In the left-hand column there are selected photos and articles, a link to the latest edition of the „Pomerania” magazine and the number of registered and anonymous users. In this column we can also find the We Recommend section with the Kaszub coat of arms, flag and holidays listed, a test on Kaszub writing, Kaszub writing on the computer and Kaszub lessons. In the right-hand column there is also a list of articles and photographs. Below is the computer Kaszub and a Kaszub 
computer keyboard. In this column are also Friendly pages, among which are The Kaszub dictionary and Associations of Young Kaszub Artists.

At the top of the page the following tabs have been placed:

- News, where news of forthcoming book promotions and other news are listed.

- Articles, divided into Education and regional activities, History, Kaszub Language Council and Literature.

- Photographs, including news, landscapes and thematic ones.

- Scans. history.

- Forum - which is sub-divided into sections on general matters, language and

- Links - with varied categories.

- Material for downloading.

- Questionnaires. One of the questionnaires worthy of attention was 'Why do you visit our site?' Of the 54 people taking part $64 \%$ of the respondents answered to follow news of Kaszuby and Pomerania, 12\% articles on Pomeranian and Kaszub matters and $11 \%$ discussions on forums.

It is worth noting that the portal is meant both for Kaszuby and to disseminate information about Kaszuby. A very important element is the discussion forum which is a space for an exchange of information and ideas to take place. We are also dealing with a community that is asserting its individuality and wishes to communicate to the wider population. What is particularly noticeable is that this activity is prompted by a sense of mission.

The association of people of Kaszub nationality is a user of Facebook and has over 1059 users who like it (as of 11.07.2013). The third case is rather different. This is the site of the Bente Kahn Foundation and the Centre for Jewish Culture and Education at the White Stork Synagogue in Wroclaw. The Foundation started its activity in 2006 with the aim of restoring the White Stork Synagogue and the aim of creating Jewish education and culture centre. The founder, Bente Kahn, is a Norwegian actress and singer of Jewish origin and is now one of the foremost singers of Jewish songs in Europe. The page is in three languages - Polish, German and English and there are the following tabs on the first page:

- Foundation. Information about the foundation, team and how to become a volunteer.

- Synagogue. Information about the history and opening of the Synagogue and its reclaiming.

- Current affairs. Information about current events in the Synagogue.

- Projects. This tab is sub-divided into the following categories. Centre of Jewish Education and culture, White Stork Gallery, Mutual Respect Days, Summer at 
the White Stork Synagogue, Educational events and a permanent exhibit entitled 'History Regained'.

- Gallery - photos of the synagogue and events taking place there.

- Contact - Diary of events.

Forthcoming events planned for the month ahead have a central position on the page. The site is very different from the two analyzed above. The main aim is the promotion of events, cultural events organized by the Foundation and undertakings aimed at promoting Jewish culture. This means promotion of the language, holidays and Jewish customs. This activity is more aimed at promoting inter-cultural dialogue and reconciliation. What is significant are activities aimed at building knowledge and recognition of the White Stork synagogue itself.

The Foundation can also be found on Facebook, Youtube and Twitter.

At the end of the analysis of these selected examples I would also like to point to another interesting project, disseminated with the aid of on-line tools. What I have in mind is the social campaign of Prom (Ferry) Social Integration Foundation- 'One of Many'.

This project is co-financed by the European Union within the Social Fund. The project by Chad Evens-Wyatt- entitled Roma Rising, about the Roma living in the Czech Republic. The Prom Social Integration Foundation decided to launch an analogous project in Poland named Roma Rising.pl At the beginning there was an album of photos taken by Chad Evans Wyatt, who photographed Roma people throughout the country. These people, also began to figure as the faces of the campaign entitled 'One of Many' Its aim is to change the attitudes to the Roma minority that prevail in Poland. 'One of Many'are the Roma, who in the view of the campaign organisers, have achieved social and professional status with acceptance by society in general. They portraits of the Roma are presented with the aim of showing the wider audience how important is the role of social integration and coexistence in a local environment. The tools that have been used have included the internet, including social media sites, billboards, radio ads and press articles ${ }^{1}$.

I would like to mention one more event here, namely the National Census carried out in Poland in 2011. It concerns all the minorities and it demonstrated that the internet had not been utilized to a sufficient degree in the past as a tool of communication, promotion and what inequalities could be experienced by users. For the first time citizens were able to file their entries to the census using the net.

„The innovative way of conducting the census with the use of modern techniques opened new possibilities, but also, in the absence of information entailed certain risks", according to P.Tyma chairman of the Union of Ukrainians in Poland.

${ }^{1}$ Zob. więcej www.jednizwielu.pl (10 IX 2012). 
„The failure to conduct a wide and multi-faceted campaign of information meant that a chance to interest more citizens in the census was lost"'.

In context of the NSP it is worth pointing to one of the first campaigns of this type in Poland. The Ukrainian Union received a grant from the Batory Foundation. Apart from leaflets in Polish and Ukrainian funds from the grant were used to buy modems for volunteers and a special website was designed. On the www.perepys.pl page there was information about the census, links to the GUS (Central Statistical Office) pages and other state institutions involved in the census, links to press articles, radio and TV broadcasts on the subject of the census. Volunteers also conducted an information campaign on social media sites including their own site- www.hazard.net ${ }^{3}$.

In my opinion the ethnic minorities could have been expected to use the web more extensively to exchange information and shape opinion on the subject of the problems concerning these communities at the time of the census.

\section{UNCRITICALLY IN THE NET?}

The cases listed above are proof that the internet can not be viewed uncriti- cally. It is worth to refer once more to J. Van Dijk who noted there has always been inequality on social network sites. „When these were supplemented media webs, a new extension of this phenomenon appeared. The technology that we use is divided, both in terms of its physical accessability, IT skills and their use in practice. In the most extreme examples IT exclusion (in terms of access, skills and use) can be transformed into structural inequalities" (Van Dijk, 2010, p. 63).

G. Murdock is of the view that there are two forms of inequalities. „The first is simply the one between the IT haves and IT have-nots with a significant minority permanently lacking access to the new technologies. The second form shows the gap between the quality and power of the communication capacity of goods available to groups of consumers with different purchasing power at their disposal" (Murdock, 2010, p. 121). This means that people on lower incomes often have inferior and more limited products. They are less able to replace their equipment or upgrade their software on a regular basis.

As experience has shown in many countries in the case of the Roma the internet can be, at the same time a useful tool as well as a barrier to communication. The Roma very often face many social problems in the places where they live. They often live in very difficult conditions and it is unrealistic to expect such a group to have unlimited access to the internet. It is a tool, which divides, in this case between those

\footnotetext{
${ }^{2}$ Interview with Piotr Tyma, chairman of the Union of Ukrainians in Poland, Warszawa, 29.10.2011

${ }^{3}$ Raport Narodowy Spis Powszechny Ludności i Mieszkań 2011 w ocenie mniejszości ukraińskiej, Warsza- wa, wrzesień 2011.
} 
few who use it and the majority who do not have access to this type of communication. This is a problem that affects many groups. We experience inequalities on the net in terms of social, racial, gender and age divisions.

With the awareness of the significance of the new media for many communities it is worth noting some of the dangers that stem from communication on the net. The interactive media are deeply immersed in society so it is difficult to ensure their independence and maintain the highest standards. This does not, however, mean that quality and objectivity remain important criteria in assessing the supply of information. „On the net everyone can be both a recipient and supplier of information. Everyone can practice their own journalism, have their own blog, moblog or be a paparazzo. This means that every user has the potential to define people, things and phenomena according to their own concepts and meanings" (Krzysztofek, 2007, p. 234).

As K.Krzysztofek notes this why the internet is cluttered with a lot of rubbish and it is easy to get lost in this without intellectual guidance. For this, among other reasons, that multi-media education is necessary for the young in order to help them use the internet as a repository of useful information and not sifting through rubbish. The same problem is cited by A.Keen who is not interested in the whole net but just a part of it called Web 2.0. He writes, ,the dawning of the age of the amateur has blurred the distinction between the reader and writer, artist and opinion shaper, art and product, amateur and expert" (Keen, 2007, p. 45). This, according to the writer, has an influence on the quality and value of the informa- tion we receive.

\section{CONCLUSION}

It is still too early to make any conclusions regarding the long-term effects of the Internet in multiethnic communities. But in the global communication era the Internet is typically used to strengthen, rather than weaken national identities.

Ethnic and religious groups rightly view the internet as an alternative information tool This is linked with the difficulty in reaching the public and commercial media and also the image that these groups have in the mainstream media. This form of communication opens new possibilities in giving shape to new transnational communities, international communication and building new identities. The internet, which is borne out by a wide body of research also reinforces existing identities shaping new relationships within groups. According to K.Krzysztofek views the internet as a metamedium, which absorbs interpersonal communication, which is institutional and on a mass scale.

The internet is not a risk for other media and does not destroy them, but changes their nature. The cases discussed in the text are proof of the different forms of communication used by ethnic communities. The web sites, which were subjects of the analyses provide a platform to communicate with their own community as well as 
outside. There are also different forms of promoting one's own undertakings. A form that is used more and more often are discussion forums.

What is clear, however, is that ethnic communities in Poland reach for the new tools on offer in different ways. Not all of them notice of their huge potential and access to them varies from community to community.

In this paper I confront different approaches to the subject, rooted in political science, intercultural communication, mass media communication. The main questions of this article ask what the practice of network communication by ethnic communities in Poland. I present three main cases illustrating the process of implementing the network communication and how different tools are used to create the multiethnic public sphere. I have also attempted to explain the reasons and, most importantly, the consequences of Internet communication in Polish ethnic and national minorities.

\section{LITERATURE}

Bailey, O., Cammaerts, B., Carpentier, N. (2012), Alternative Media, Kraków (in Poland).

Castells M., Społeczeństwo sieci, Warszawa.

Eriksen, T. (2011), Nations in cyberspace, http://www.media-anthropology.net/ eriksen_nationscyberspace, [15.12.2011]

Gustowski, W. (2012), Communication on social media, Gdynia (in Poland).

Interview with Piotr Tyma, chairman of the Union of Ukrainians in Poland, Warszawa, 29.10.2011.

Keen, A. (2007), Amateur cult. How the internet destroys culture, Warszawa (in Poland).

Krzysztofek, K. (2007), Status of digital media: old and new paradigms, red. J.Fras, Studia nad komunikacją popularną, międzykulturową, sieciową i edukacyjną, Toruń (in Poland).

Levinson, P. (2010), New media, transl.M. Zawadzka, Kraków (in Poland).

Maffesoli, M. (2008), Time of the tribes. Decline of individualism in post-modern societies, Warszawa (in Poland).

Murdock, G. (2010), Media, culture and economy. Critical questions, Text anthology, selection and preface J.Fras, Wrocław (in Poland).

Nowak, A., Krejtz K. (2006), The Internet from the perspective of social sciences, red. Batorski D., Marody Nowak A., The social space of the Internet, Warszawa (in Poland).

The 2011 National Census of Population and Housing Report as assessed by the Ukrainian minority, Warszawa, september 2011. (in Poland)

Van Dijk, J. (2010), Social aspects of new media. Network society analysis, Warszawa (in Poland). 
Vittadini, N., Milesi, D., Aroldi, P. (2013), „New-Generation Ties: Identity, Social Relations and Digital Technologies among 2G Migrants in Italy“, Observatorio Journal, Special Issues.

Wawrzak-Chodaczek, M. (2012), „Social networks as a place of local communication in global networks", Culture-History-Globalization, No. 13. Wywia-d z W.Bursztą, Tęsknota za drugim człowiekiem, „Computer-world”, 27.12. 2005, [11.12.2012] (in Poland) 